\title{
Experimental
}

\section{General Conditions}

\section{Synthesis:}

Nuclear magnetic resonance (NMR) spectra were acquired using a Bruker AV 500 $\left({ }^{1} \mathrm{H}\right.$ at $500.13 \mathrm{MHz}$ and ${ }^{13} \mathrm{C}$ at $\left.125.8 \mathrm{MHz}\right)$ or a Bruker AV $600\left({ }^{1} \mathrm{H}\right.$ at $600.13 \mathrm{MHz}$ and ${ }^{13} \mathrm{C}$ at $\left.150.9 \mathrm{MHz}\right)$. Chemical shifts are reported relative to the residual solvent peak in $\mathrm{CD}_{3} \mathrm{OD}$. Assignments were made with the aid of either the DEPT or HSQC techniques.

Mass spectra were recorded using the electrospray technique (positive ion trap) on a VG Autospec instrument.

Microanalyses for carbon, nitrogen, and hydrogen were carried out by The Australian National University Microanalytical Service. All samples were thoroughly dried under vacuum at $50{ }^{\circ} \mathrm{C}$ for at least $4 \mathrm{~h}$ prior to their analysis.

\section{Synthetic Details:}

3,4,5-Tris(n-dodecan-1-yloxy)benzoic acid:

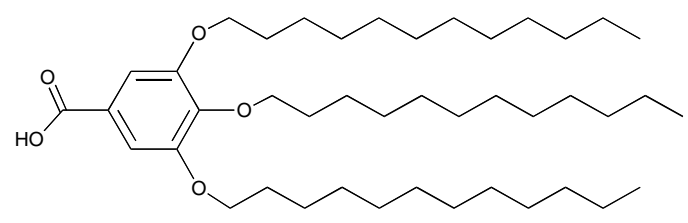


This compound was prepared via modification of a literature procedure. \{Percec, 1999 \#191\} Ethyl 3,4,5-trihydroxy benzoate (5.8 g, $34 \mathrm{mmol})$ and $\mathrm{K}_{2} \mathrm{CO}_{3}(28 \mathrm{~g}, 200 \mathrm{mmol})$ were stirred under nitrogen in deoxygenated DMF $(150 \mathrm{~mL})$. The mixture was stirred vigourously whilst 1-bromododecane $(35 \mathrm{~mL}, 145 \mathrm{mmol})$ was added dropwise. Once the addition was complete, the mixture was heated at $60{ }^{\circ} \mathrm{C}$ for $12 \mathrm{~h}$ under $\mathrm{N}_{2}$, then allowed to cool to RT before being poured into ice $/ \mathrm{H}_{2} \mathrm{O}$, causing a white precipitate to float to the surface. The mixture was filtered on a sintered glass frit, and the white solid washed with copious quantities of water and then allowed to dry in air. The solid was then dissolved in DCM and passed through a short column of basic $\mathrm{Al}_{2} \mathrm{O}_{3}$, using DCM as the eluant. The solution was brought to dryness on the rotary evaporator, dissolved in n-hexane and applied to a short column of silica gel. The column was washed with n-hexane to remove excess 1-bromododecane, and the product removed in $20 \%$ EtOAc/n-hexane. Removal of the solvent under vacuum gave ethyl-3,4,5tris(n-dodecan-1-yloxy)benzoate $(14.6 \mathrm{~g}, 21 \mathrm{mmol})$ as a white powder.

${ }^{1} \mathrm{H}$ NMR $\left(\mathrm{CDCl}_{3}, 500 \mathrm{MHz}\right): 0.88\left(\mathrm{t}, 9 \mathrm{H}, 3\left(-\mathrm{CH}_{3}\right)\right), 1.2-1.4(\mathrm{~m}, 48 \mathrm{H} 3(-$ $\left.\left.\mathrm{OCH}_{2} \mathrm{CH}_{2} \mathrm{CH}_{2}\left(\mathrm{CH}_{2}\right)_{8}\right)\right), 1.38\left(\mathrm{t}, 3 \mathrm{H},-\mathrm{CO}_{2} \mathrm{CH}_{2} \mathrm{CH}_{3}\right), 1.47$ (m, 6H 3(- $\left.\left.\mathrm{OCH}_{2} \mathrm{CH}_{2} \mathrm{CH}_{2}-\right)\right)$, $1.73\left(\mathrm{~m}, 2 \mathrm{H}, p-\mathrm{OCH}_{2} \mathrm{CH}_{2^{-}}\right), 1.81\left(\mathrm{~m}, 4 \mathrm{H}, 2\left(m-\mathrm{OCH}_{2} \mathrm{CH}_{2}-\right)\right), 4.01$ (t, 6H, 3(-OCH $\left.\left.2^{-}\right)\right)$, 4.35 (q, 2H, (- $\left.\mathrm{CO}_{2} \mathrm{CH}_{2}-\right), 7.22$ (s, 2H, 2( $\left.\left.\mathrm{ArCH}\right)\right)$.

Ethyl-3,4,5-tris(n-dodecan-1-yloxy)benzoate (14.0 g, $20 \mathrm{mmol})$ and $\mathrm{KOH}(8.0 \mathrm{~g}, 143$ mmol) were added to a round bottom flask containing EtOH $(200 \mathrm{~mL})$. The mixture was heated at reflux for $3 \mathrm{~h}$, and the reaction progress monitored by TLC. After allowing the solution to cool to room temperature, conc. $\mathrm{HCl}$ was added until the solution reached $\mathrm{pH}$ 1-2 as determined by universal indicator paper. The solution was then poured into a beaker of ice/water $(1 \mathrm{~L})$, producing a white precipitate which was 
filtered and washed with copious quantities of water and then dried under vacuum to give 3,4,5-tris(n-dodecan-1-yloxy)benzoic acid (12.4 g, $18 \mathrm{mmol}$ ) as a white powder. ${ }^{1} \mathrm{H}$ NMR $\left(\mathrm{CDCl}_{3}, 500 \mathrm{MHz}\right): 0.88\left(\mathrm{t}, 9 \mathrm{H}, 3\left(-\mathrm{CH}_{3}\right)\right), 1.20-1.40$ (m, 48H 3($\left.\mathrm{OCH}_{2} \mathrm{CH}_{2} \mathrm{CH}_{2}\left(\mathrm{CH}_{2}\right)_{8}\right), 1.48\left(\mathrm{~m}, 6 \mathrm{H}, 3\left(-\mathrm{OCH}_{2} \mathrm{CH}_{2} \mathrm{CH}_{2}-\right)\right), 1.76\left(\mathrm{~m}, 2 \mathrm{H}, p-\mathrm{OCH}_{2} \mathrm{CH}_{2}-\right.$ ), $1.82\left(\mathrm{~m}, 4 \mathrm{H}, 2\left(m-\mathrm{OCH}_{2} \mathrm{CH}_{2^{-}}\right)\right), 4.02\left(\mathrm{t}, 4 \mathrm{H}, 2\left(m-\mathrm{OCH}_{2^{-}}\right)\right), 4.05\left(\mathrm{t}, 2 \mathrm{H}, p-\mathrm{OCH}_{2^{-}}\right)$, $7.33(\mathrm{~s}, 2 \mathrm{H}, 2(\mathrm{ArCH}))$.

${ }^{13} \mathrm{C} \mathrm{NMR}\left(\mathrm{CDCl}_{3}, 125 \mathrm{MHz}\right): 14.27\left(-\mathrm{CH}_{3}\right), 22.85,26.20,26.24,29.44,29.53,29.55$, $29.72,29.79,29.82,29.86,29.88,29.89,29.91,30.49,32.09,32.10\left(-\mathrm{CH}_{2^{-}}\right), 69.34$ $\left(m-\mathrm{Ar}-\mathrm{OCH}_{2}-\right), 73.71\left(p-\mathrm{Ar}-\mathrm{OCH}_{2}-\right), 108.72$ (o-ArCH), 123.75 (i-ArC), 143.34 (pArC), 153.01 (m-ArC), $172.04(\mathbf{C}=\mathrm{O})$.

Synthesis of 1:

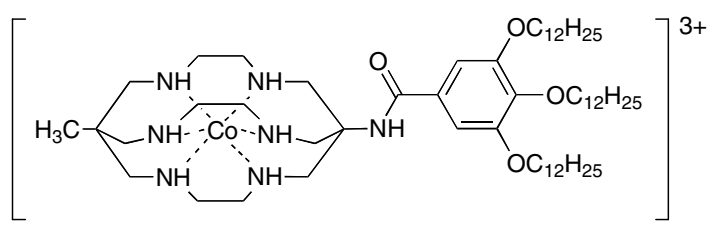

3,4,5-Tris(n-dodecan-1-yloxy)benzoic acid (1.60 g, $2.37 \mathrm{mmol})$ was dissolved in $c a$. $10 \mathrm{~mL}$ of $\mathrm{SOCl}_{2}$ and the solution heated at reflux under $\mathrm{N}_{2}$ for 3 hours. The solvent was then removed under reduced pressure to give a light brown solid. The solid was gently heated until molten, and then a solution of $\left[\mathrm{Co}\left(\mathrm{CH}_{3}\right)\left(\mathrm{NH}_{3}\right) \mathrm{sar}\right]\left(\mathrm{CF}_{3} \mathrm{SO}_{3}\right)_{4}\{\mathrm{Geue}, 1984 \# 88\}(1.45 \mathrm{~g}, 1.5 \mathrm{mmol})$ and $\mathrm{NEt}_{3}(3 \mathrm{~mL})$ in DMA (7 mL) was added to the liquid and the mixture was stirred vigourously under $\mathrm{N}_{2}$. After $c a .1 \mathrm{~h}$ an orange precipitate had begun to form, and stirring was continued overnight. The reaction was deemed complete when a small aliquot of the mixture dissolved in DCM and gently extracted with $1 \mathrm{M} \mathrm{HCl}_{(\mathrm{aq})}$ gave no visible colour in the aqueous phase. After the reaction was complete, an excess of $\mathrm{MeOH}$ was added to the mixture and stirring continued for another hour, after which the 
mixture was poured into DCM (ca. $250 \mathrm{~mL})$ and gently extracted with $0.5 \mathrm{M} \mathrm{HCl}_{(\mathrm{aq}}$ (5 x ca. $200 \mathrm{~mL}$ ) and the aqueous layer discarded (vigorous extraction led to very stable emulsions which would not separate even after days). The organic layer was brought to dryness on the rotary evaporator to give an orange oil which was applied to a short column of silica. The column was washed with n-hexane/EtOAc (50:50), giving a brown/orange band that eluted with the solvent front, followed by EtOAc, $\mathrm{CHCl}_{3} / \mathrm{EtOAc}(50: 50)$, and $\mathrm{CHCl}_{3}$. Finally the orange complex was removed from the column by elution with a mixture of $\mathrm{CHCl}_{3} / \mathrm{CH}_{3} \mathrm{CO}_{2} \mathrm{H} / 0.1 \mathrm{M} \mathrm{NaOAc}$ in $\mathrm{MeOH}$ $(2: 1: 2)$ which gave one broad orange band followed by a very small yellow band. The major orange band was collected, diluted into DCM (ca. $250 \mathrm{~mL}$ ) and gently extracted with $\mathrm{H}_{2} \mathrm{O}(5 \times \mathrm{ca} .200 \mathrm{~mL})$, and the aqueous phase discarded. The organic layer was brought to dryness on the rotary evaporator and the orange solid thus obtained dissolved in $\mathrm{MeOH}$ before being passed through a column of Dowex 1 x 8 anion exchange resin (acetate form). The solvent was then removed on the rotary evaporator, and the orange oily residue dried under vacuum for 48 hours. The solid was recrystallised by dissolution in hot $\mathrm{MeCN}$, filtering and allowing to cool to RT before being stored at $-20{ }^{\circ} \mathrm{C}$ overnight. The supernatant solution was decanted from the waxy orange solid, which was washed twice with more cold MeCN before being dried under vacuum to give 1. $\left(\mathrm{CH}_{3} \mathrm{CO}_{2}\right)_{3} \cdot\left(\mathrm{H}_{2} \mathrm{O}\right)_{1.5}$ as a waxy orange solid $(0.49 \mathrm{~g}, 0.4$ mmol).

${ }^{1} \mathrm{H}$ NMR $\left(\mathrm{CD}_{3} \mathrm{OD}, 600 \mathrm{MHz}\right): 0.89$ (s, 3H, cage $\left.-\mathrm{CH}_{3}\right), 0.90$ (t, 9H, 3(alkyl -CH $\left.\mathbf{H}_{3}\right)$ ), $1.25-1.45\left(\mathrm{~m}, 54 \mathrm{H}, 18\left(\right.\right.$ alkyl $\left.\left.-\mathrm{CH}_{2^{-}}\right)\right), 1.52\left(\mathrm{~m}, 6 \mathrm{H}, 3\left(\right.\right.$ alkyl $\left.\left.-\mathrm{CH}_{2^{-}}\right)\right), 1.72(\mathrm{~m}, 2 \mathrm{H}, p-$ $\left.\mathrm{Ar}-\mathrm{OCH}_{2} \mathrm{CH}_{2-}^{-}\right), 1.81$ (m, 4H, 2(m-Ar-OCH $\left.\mathrm{CH}_{2}^{-}\right)$), 1.97 (s, 9H, 3( $\left.\left.\mathrm{CH}_{3} \mathrm{CO}_{2}^{-}\right)\right), 2.22$, $2.75-3.10,3.51\left(\mathrm{~m}, 24 \mathrm{H}\right.$, cage $\left.-\mathrm{CH}_{2^{-}}\right), 3.98\left(\mathrm{t}, 2 \mathrm{H},\left(p-\mathrm{Ar}-\mathrm{OCH}_{2^{-}}\right)\right), 4.02(\mathrm{t}, 4 \mathrm{H}, 2(m-$ $\left.\left.\operatorname{Ar}-\mathrm{OCH}_{2}-\right)\right), 7.05(\mathrm{~s}, 2 \mathrm{H}, 2(\mathrm{ArCH}))$. 
${ }^{13} \mathrm{C}$ NMR $\left(\mathrm{CD}_{3} \mathrm{OD}, 150 \mathrm{MHz}\right): 14.52\left(\right.$ alkyl $\left.-\mathrm{CH}_{3}\right), 20.74\left(\right.$ cage $\left.-\mathrm{CH}_{3}\right), 23.77,23.79$ (alkyl $-\mathrm{CH}_{2}-$ ), $24.05\left(\mathrm{CH}_{3} \mathrm{CO}_{2}^{-}\right), 27.21,27.36,30.54,30.56,30.57,30.75,30.79$, $30.84,30.88,30.91,30.95,31.45,33.12,33.14\left(\right.$ alkyl $\left.-\mathrm{CH}_{2}-\right), 43.15(\mathbf{C}$ of cage methyl cap), 52.87, 56.02, 56.48, 56.92 (cage $-\mathrm{CH}_{2}-$ ), 60.22 ( $\mathbf{C}$ of cage amide cap), $70.20\left(m-\mathrm{Ar}-\mathrm{OCH} 2^{-}\right), 74.44$ (p-Ar- $\left.\mathrm{OCH}_{2}-\right), 107.33$ (o-ArCH), 130.56 (i-ArC), 142.28 (p-ArC), 154.12 (m-ArC), 170.18 (amide $\mathbf{C}=\mathrm{O}), 181.60\left(\mathrm{CH}_{3} \mathbf{C O}_{2}{ }^{-}\right)$.

ESMS $m / z 513.92=\left[\mathrm{CoN}_{7} \mathrm{C}_{58} \mathrm{H}_{111} \mathrm{O}_{4}-\mathrm{H}^{+}\right]^{2+} ; 1026.78=\left[\mathrm{CoN}_{7} \mathrm{C}_{58} \mathrm{H}_{111} \mathrm{O}_{4}-2 \mathrm{H}^{+}\right]^{+} ;$ $1086.85=\left[\mathrm{CoN}_{7} \mathrm{C}_{58} \mathrm{H}_{111} \mathrm{O}_{4}-\mathrm{H}^{+}+\mathrm{CH}_{3} \mathrm{CO}_{2}^{-}\right]^{+}$.

Analysis (Found C, 61.96; H, 9.76; N, 7.57. Calc. for $\left[\mathrm{CoN}_{7} \mathrm{C}_{58} \mathrm{H}_{111} \mathrm{O}_{4}\right]\left(\mathrm{CH}_{3} \mathrm{CO}_{2}\right)_{3}\left(\mathrm{H}_{2} \mathrm{O}\right)_{1.5}=\mathrm{CoN}_{7} \mathrm{C}_{64} \mathrm{H}_{123} \mathrm{O}_{11.5}: \mathrm{C}, 62.31 ; \mathrm{H}, 10.05 ; \mathrm{N}$, 7.95).

Synthesis of 2:

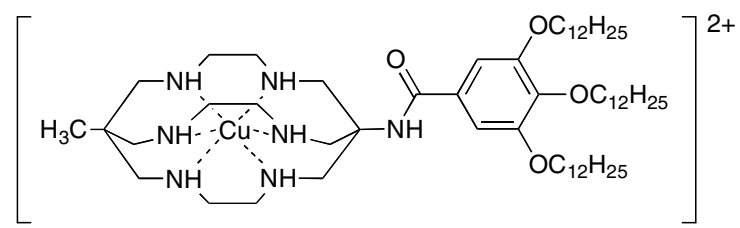

3,4,5-Tris(n-dodecan-1-yloxy)benzoic acid (2.0 g, $3.0 \mathrm{mmol})$ was dissolved in $\mathrm{SOCl}_{2}$ (ca. $10 \mathrm{~mL}$ ) and the solution heated at reflux for 3 hours under $\mathrm{N}_{2}$. The solvent was then removed under reduced pressure to give a light brown solid. The solid was gently heated until it melted, and to this liquid was added a solution of $\left[\mathrm{Cu}\left(\mathrm{CH}_{3}\right)\left(\mathrm{NH}_{2}\right) \operatorname{sar}\right]\left(\mathrm{ClO}_{4}\right)_{2}\left(\mathrm{HClO}_{4}\right)_{0.5}(1.00 \mathrm{~g}, 1.60 \mathrm{mmol})$ and $\mathrm{NEt}_{3}(3 \mathrm{~mL})$ in DMA $(15 \mathrm{~mL})$, producing a white precipitate immediately, and the mixture was stirred vigorously for $18 \mathrm{~h}$. After this time, there was a significant quantity of a blue precipitate, giving a milky blue mixture, and the reaction was deemed complete as a small aliquot of the mixture was dissolved in DCM and extracted with $1 \mathrm{M} \mathrm{HCl}_{(\mathrm{aq})}$, 
giving no colour in the aqueous phase. $\mathrm{MeOH}(c a .15 \mathrm{~mL})$ was added and the mixture stirred for $2 \mathrm{~h}$, after which time it was diluted with DCM (ca. $250 \mathrm{~mL})$ and extracted with $1 \mathrm{M} \mathrm{HCl}(3 \times 250 \mathrm{~mL})$. This procedure gave a slightly purple/violet colour to the organic phase, which was brought to dryness on the rotary evaporator, leaving a purple/blue solid. The residue was dissolved in 50\% EtOH/DCM and applied to a column of silica. The column was washed sequentially with n-hexane, 50\% EtOAc/nhexane, EtOAc, $50 \% \mathrm{EtOAc} / \mathrm{CHCl}_{3}, \mathrm{CHCl}_{3}$ and the desired complex eluted from the column with a mixture of $\mathrm{CHCl}_{3} / \mathrm{CH}_{3} \mathrm{CO}_{2} \mathrm{H} / 0.1 \mathrm{M} \mathrm{NaOAc}$ in $\mathrm{MeOH}(2: 1: 2)$ as a broad blue band. The blue eluate was gently extracted with water ( $3 \times 250 \mathrm{~mL})$, and the organic phase brought to dryness on the rotary evaporator, giving a blue solid. The residue was dissolved in $\mathrm{Et}_{2} \mathrm{O}$ and gently extracted with $1 \mathrm{M} \mathrm{HCl}_{(\mathrm{aq})}$, causing immediate precipitation of a blue solid, which settled at the boundary between the organic and aqueous phases. Most of the aqueous phase was drained from the separatory funnel, and the remaining mixture filtered though a sintered glass frit. The blue solid was washed copiously with water and finally $\mathrm{MeCN}$ and allowed to air dry. The solid was recrystallised from hot $\mathrm{CHCl}_{3}$ by the addition of acetone to give 2. $\mathrm{Cl}_{2} . \mathrm{HCl}$ as a blue powder $(1.21 \mathrm{~g}, 1.1 \mathrm{mmol})$.

ESMS: $m / z 516.40=\left[\mathrm{CuC}_{58} \mathrm{H}_{111} \mathrm{~N}_{7} \mathrm{O}_{4}\right]^{2+} ; 1067.77=\left[\mathrm{CuC}_{58} \mathrm{H}_{111} \mathrm{~N}_{7} \mathrm{O}_{4}+\mathrm{Cl}^{-}\right]$. Analysis (Found C, 61.07; H, 9.14; N, 8.32. Calc. for $\left[\mathrm{CuN}_{7} \mathrm{C}_{58} \mathrm{H}_{111} \mathrm{O}_{4}\right] \mathrm{Cl}_{2}(\mathrm{HCl})=$ $\left.\left[\mathrm{CuN}_{7} \mathrm{C}_{58} \mathrm{H}_{112} \mathrm{O}_{4} \mathrm{Cl}_{3}\right]: \mathrm{C}, 61.03 ; \mathrm{H}, 9.89 ; \mathrm{N}, 8.59\right)$.

Conversion to the acetate salt was accomplished by passing a solution of the complex in $\mathrm{MeOH}$ through a column of Dowex $1 \times 8$ anion exchange resin (acetate form) and recrystallising from $\mathrm{MeCN}$.

Critical Micelle Concentration (CMC) for $\mathbf{1}$. 


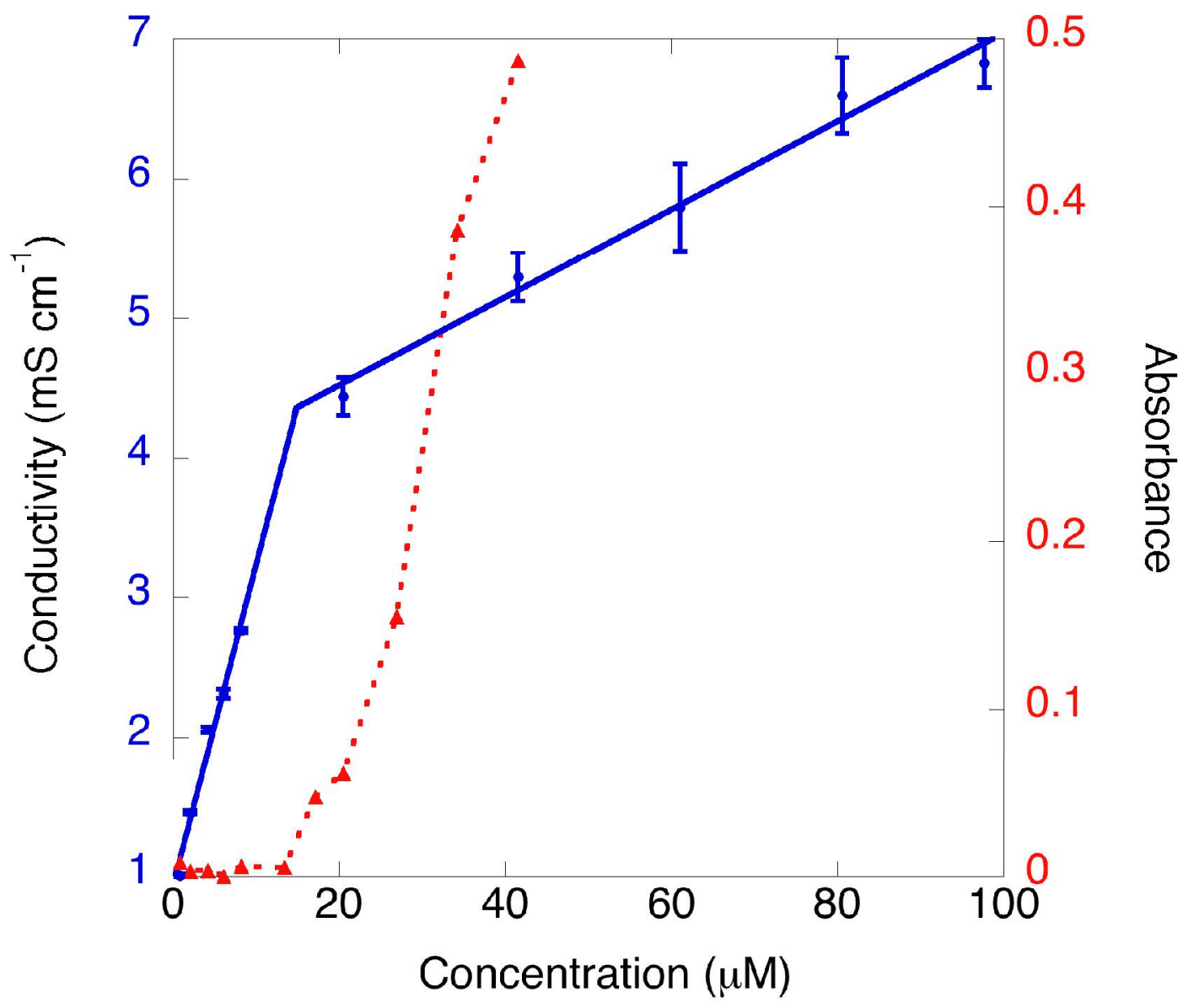

Figure 1. CMC determination using conductivity (left axis) and dye absorbance (right axis).

Conductivity measurements: A stock solution of complex $\mathbf{1}$ was prepared in water that had been purified by a Milli-Q Ultra-Pure Water System, and the analyte solutions were obtained by dilution of this stock. The conductivity of each solution was determined using a PTI-18 Digital Conductivity Meter and TPS Conductivity Sensor. The analyte solutions were maintained at $25.00 \pm 0.05{ }^{\circ} \mathrm{C}$ by immersion in a constant temperature bath and the conductance at each concentration was recorded after it remained constant with time (ca. $30 \mathrm{~min})$.

Dye-micellisation method: Solid 5(4-dimethylaminobenzylidene)rhodanine dye was added to solutions of $\mathbf{1}$ at varying concentrations, and the mixtures sonicated for $c a$. 20 mins before being filtered into a $1 \mathrm{~cm}$ path length quartz cuvette. Spectra were 
recorded on a Hewlett-Packard 8452A diode array spectrophotometer and the intensity of the peak at $\lambda=450 \mathrm{~nm}$ was plotted as a function of concentration to give the red curve shown above. The dotted line is a visual aid for the reader.

\section{Transmission Electron Microscopy:}

Samples prepared for the negative stained images were prepared as follows: A drop of the solution was placed on a formvar coated $\mathrm{Cu}$ grid which had been previously treated to a glow discharge procedure to enhance wettability of the substrate. The solution was allowed to stand for 1 minute before being blotted with the tip of a filter paper. A solution of $1 \%$ aqu. uranyl acetate was then added to the sample, allowed to stand for 1 minute before being blotted and subsequently allowed to dry in air. Samples for the cryo-TEM work were prepared using a controlled environment vitrification system (Vitrobot ${ }^{\mathrm{TM}}$, FEI, Eindhoven, NL), which allowed the samples to be prepared at $25{ }^{\circ} \mathrm{C}$ and $100 \%$ relative humidity to prevent solvent evaporation. A drop of the solution was placed on a quantifoil ${ }^{\mathrm{TM}}$ grid $(\mathrm{R} 2 / 4, \mathrm{Cu}=400 \mathrm{mesh})$, blotted for 2 seconds, and the grid plunged into a bath of ethane maintained at its freezing point with a bath of liquid $\mathrm{N}_{2}$. Electron microscopy: Grids containing frozen thin films of surfactant were cryotransferred at $-180{ }^{\circ} \mathrm{C}$ temperature to a Gatan 626 cryoholder (Gatan, Warrendale, PA, USA). Vitrification of the specimen was tested by electron diffraction. Thin films were imaged at 80-120 keV using an FEI Tecnai 12 electron microscope equipped with photographic film and a Mega View III CCD camera (Soft Imaging Systems) respectively or on a $300 \mathrm{keV}$ FEI Tecnai F30 equipped with a Gatan 4 x 4K CCD. 
Film exposures were calculated at minimal beam exposure conditions $(<1000$ electrons per $\mathrm{nm}^{2}$ per micrograph). Images were recorded on Kodak SO-163 film at various magnifications and negatives were scanned on a Nikonscan 8000 densitometer.

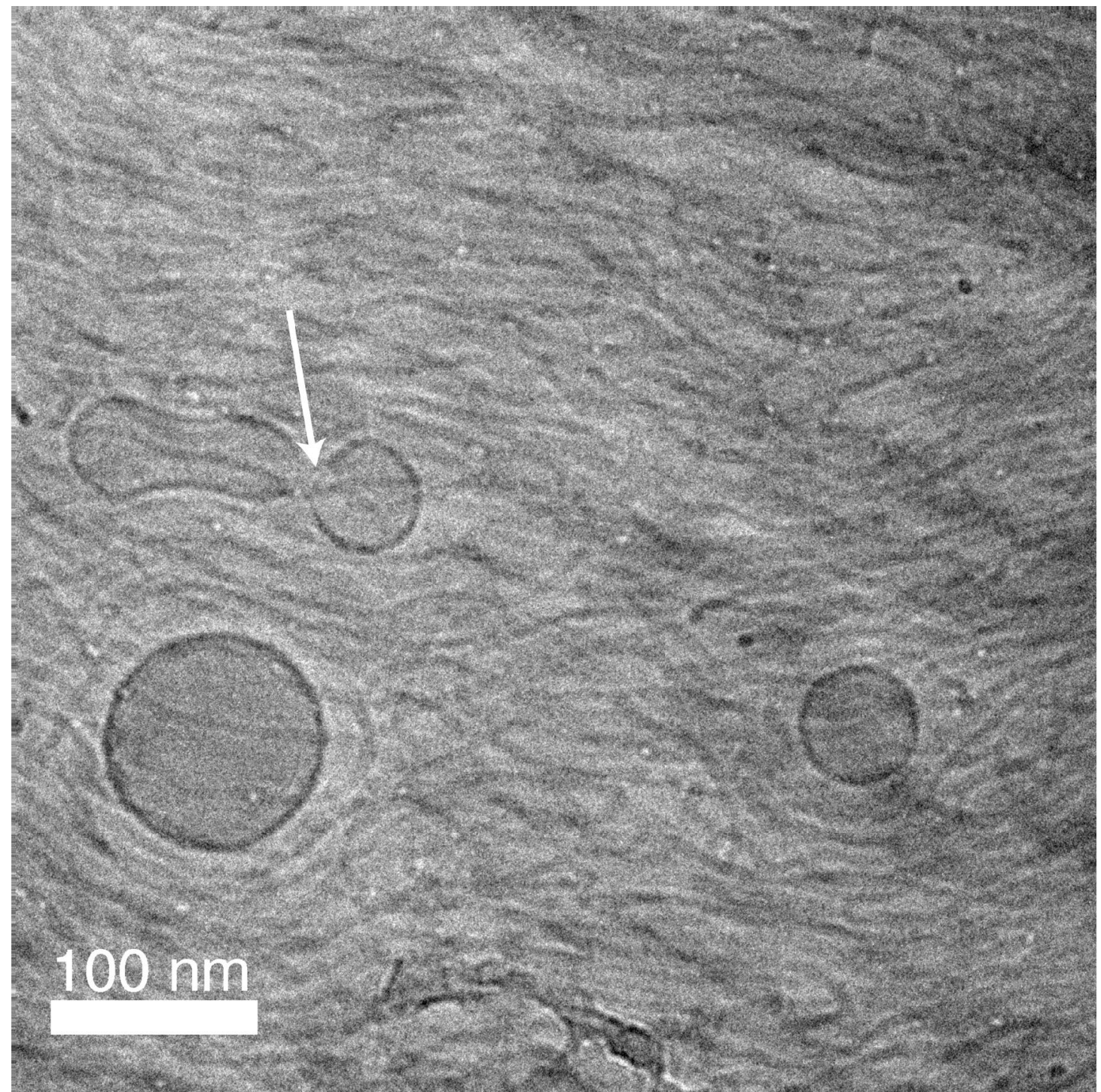

Figure 2. Cryo-TEM image of 1 at 1 wt.\% showing the coexistence of vesicles and wormlike micelles. The arrow points to an open edge of the vesicle. 


\section{SAXS measurements}

The SAXS patterns were measured with the NanoSTAR SAXS instrument at Curtin University. The liquid samples were sealed within glass capillaries during the measurements. Data was recorded at a sample-detector distance of $22.8 \mathrm{~cm}$ using a wavelength, $\lambda$, of $1.5418 \AA\left(\mathrm{Cu} \mathrm{K}_{\alpha}\right)$ and scattered photons were counted with a $2 \mathrm{D}$ multiwire detector for 3 hours per sample. The raw data was radially averaged, background subtracted, and was put on an absolute scale by calibrating against an S2907 standard reference pattern from Oak Ridge National Laboratory. Resulting intensities, after discarding low $q$ data points affected by the beam stop, spanned a $q$ range of 0.039 to $0.85 \AA^{-1}$ ( $q=4 \pi \sin \theta / \lambda$, where $2 \theta$ is the scattering angle). 